\title{
Review
}

CARDIOLOGY

\section{Treatment of Angina: Where Are We?}

\author{
Cristina Balla Rita Pavasini Roberto Ferrari \\ Centro Cardiologico Universitario and LTTA Centre, University Hospital of Ferrara, Ferrara, Italy; Maria Cecilia \\ Hospital, GVM Care and Research, Cotignola, Italy
}

\section{Keywords}

Angina - Beta-blockers - Calcium channel blockers .

Ivabradine - Myocardial ischaemia - Nicorandil nitrates .

Ranolazine $\cdot$ Trimetazidine

\begin{abstract}
Ischaemic heart disease is a major cause of death and disability worldwide, while angina represents its most common symptom. It is estimated that approximately 9 million patients in the USA suffer from angina and its treatment is challenging, thus the strategy to improve the management of chronic stable angina is a priority. Angina might be the result of different pathologies, ranging from the "classical" obstruction of a large coronary artery to alteration of the microcirculation or coronary artery spasm. Current clinical guidelines recommend antianginal therapy to control symptoms, before considering coronary artery revascularization. In the current guidelines, drugs are classified as being first-choice (beta-blockers, calcium channel blockers, and short-acting nitrates) or second-choice (ivabradine, nicorandil, ranolazine, trimetazidine) treatment, with the recommendation to reserve second-line modifications for patients who have contraindications to first-choice agents, do not tolerate them, or remain symptomatic. However, such a categorical approach is currently questioned. In addition, current guide-
\end{abstract}

lines provide few suggestions to guide the choice of drugs more suitable according to the underlying pathology or the patient comorbidities. Several other questions have recently emerged, such as: is there evidence-based data between first- and second-line treatments in terms of prognosis or symptom relief? Actually, it seems that newer antianginal drugs, which are classified as second choice, have more evidence-based clinical data that are more contemporary to support their use than what is available for the first-choice drugs. It follows that actual guidelines are based more on tradition than on evidence and there is a need for new algorithms that are more individualized to patients, their comorbidities, and pathophysiological mechanism of chronic stable angina.

(C) 2018 S. Karger AG, Basel

\section{Introduction}

Ischaemic heart disease continues to be the major cause of death and disability among Western countries and angina pectoris is the most prevalent symptomatic manifestation. Strategies to improve management of chronic stable angina remain a priority. Almost a third of patients have suboptimal treatment, both in terms of advice regarding lifestyle modification, as well as the appro-

\section{KARGER}

(C) 2018 S. Karger AG, Basel

E-Mail karger@karger.com

www.karger.com/crd
Roberto Ferrari, MD

Azienda Ospedaliero-Universitaria di Ferrara, Ospedale di Cona Via Aldo Moro 8

IT-44124 Cona, Ferrara (Italy)

E-Mail fri@unife.it 
Fig. 1. Possible combination of classes of antianginal drugs. Adapted from Ferrari et al. [18].

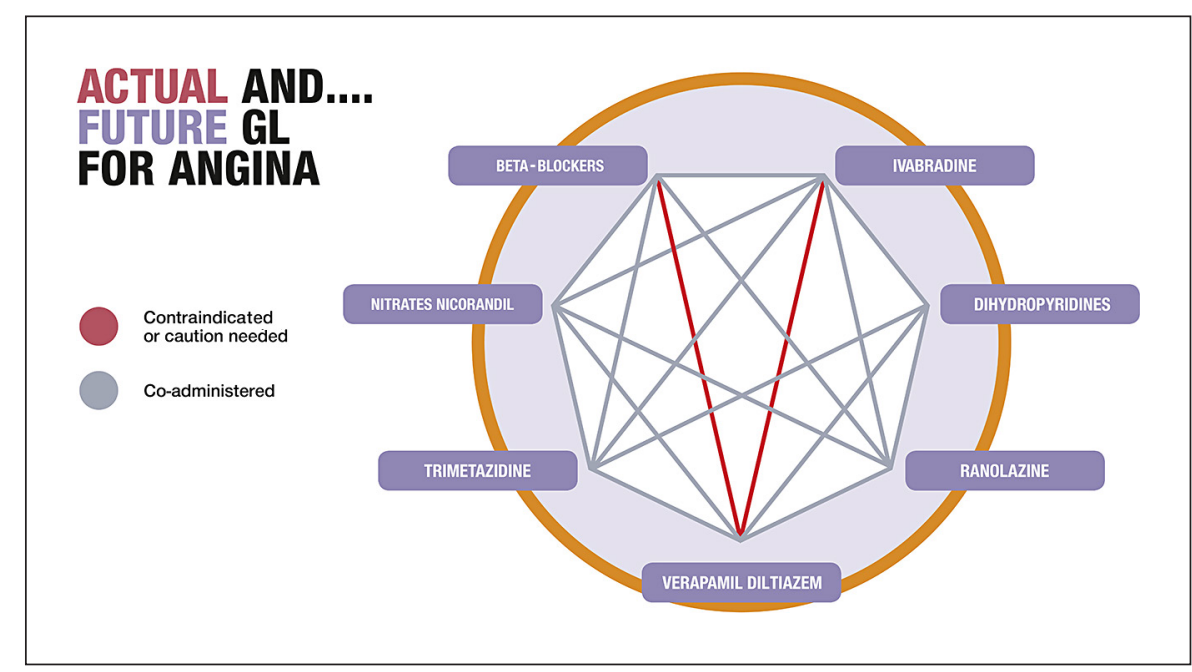

priate use of several approved antianginal drugs and/or coronary revascularization, either percutaneous or surgical [1-4].

A thorough understanding of the pathophysiology of ischaemic heart disease and angina is essential for optimal management. The exact mechanism of angina varies from patient to patient and within patients, causing a mismatch between myocardial oxygen demand and delivery. In the majority of patients, the underlying pathology is atherosclerotic narrowing of one or more epicardial coronary arteries, which limits coronary blood flow $[5,6]$. Nevertheless, angina, in a limited proportion of patients, may occur in the absence of significant coronary artery disease $(\mathrm{CAD})$ and obstructive lesions, or even in the presence of angiographically normal coronary arteries [7-9]. The underlying mechanisms of angina, in this subset of patients, are related to functional alterations of the coronary circulation at the level of the coronary microcirculation $[10,11]$.

Current guidelines recommend antianginal therapy to control symptoms, prior to considering coronary artery revascularization. Clinical randomized trials have shown that an invasive strategy of coronary revascularization, after excluding patients who had significant CAD ( $>50 \%$ left main narrowing or proximal 3 vessel disease), is not superior to optimal medical therapy [12, 13]. Antianginal agents are approved for clinical use by documenting that they increase walking effort time to angina and total exercise duration, together with a reduction of daily frequency of angina compared to placebo and/or equivalence to an active comparator. Cardiovascular outcomes, although highly advocated, are not a pre-requisite for regulatory approval. At present, pre-

Treatment of Angina: Where Are We? vention or reduction of the progression of atherosclerosis and, consequently, improvement of outcome is achieved with lifestyle modification, mainly by abstaining from smoking tobacco, and optimal control of blood pressure, diabetes, and dyslipidaemia [1-4]. Recently, it has been suggested that inflammation may also play a role and treatment with canakinumab in patients with chronic ischaemia has led to a reduction of mortality [14]. Conversely, none of the antianginal drugs (with the possible exception of nicorandil) have been proven to reduce cardiovascular mortality or myocardial infarction, despite the fact that they are equally effective in treating symptoms. Guidelines recommend a first- and a second-choice approach [1-4]. This classification, however, seems to be based more on tradition and expert opinion, rather than evidence [15-17]. Actually, newer antianginal drugs, which are classified as second line, have more evidence-based data to support their use than the traditional first-line drugs. Equally, the often needed combination of double or triple therapy is based on expert opinion and not related to the underlying pathophysiology. It follows that what constitutes optimal antianginal treatment varies considerably from one country to another and the majority of doctors treat their patients according to their own preconceptions. For this reason, an expert consensus document has been recently published with the proposition of an individualized approach to angina treatment, which take into consideration the patients with or without their comorbidities and the underlying mechanism of disease [18]. The idea has been graphically visualized as a diamond, where all drugs are represented on the same circular line, without any hierarchic order (Fig. 1). 


\section{History of Angina Pectoris}

Angina pectoris was first brought to the attention of the medical profession by William Heberden in 1772 when, at the Royal College of Physicians in London, he read his paper entitled "Some Account of the Disorders of the Breast" [19]. He wrote "There is a disorder of the breast... The seat of it, and sense of strangling and anxiety, with which is attended, may make it not improperly be called angina pectoris. Those, who are afflicted with it, are ceased [sic] while they are walking and most particularly when they walk soon after eating, with a painful and most disagreeable sensation in the breast, which seems as it would take their breathe away, if it were to increase or to continue; the moment they stand still, all this uneasiness vanishes." Heberden's initial description is still accurate, although in actual fact, there are no truly characteristic symptoms of angina pectoris, as will become apparent later on.

References to pain in the breast and arm, in relation to disease affecting the heart, were found in ancient Egyptian mummies some 3,500 years old. These have been shown by computed tomography to have had atherosclerosis [20]. Interestingly, this finding was present in mummies with a high social status. It is difficult to date when civilization first became aware of ischaemic heart disease, but it is known that Leonardo da Vinci investigated the coronary arteries (1452-1519); William Harvey (15781657) described the blood circulation, and Friedrich Hoffman (1660-1742) noticed a "reduced passage of blood within the coronary arteries," though none closed the link with angina [21].

Heberden had no clear idea of the pathophysiology of the syndrome. He suggested that it could be due to a strong cramp, or an ulcer, or possibly both. Edward Jenner was probably the first to notice an association of angina with CAD. In 1776 he wrote to Heberden describing 2 hearts which he had examined from patients who had died of angina. He described the coronary arteries with these words: "a fleshy tube with a considerable quantity of ossific material dispersed irregularly through it" [21]. Other theories, still valid today, included coronary spasm as a cause of angina. Lauder Brunton thought angina to be due to a spasm of coronary vessels, and others linked it to irritation of the nervous elements of the cardiac plexus [21].

The diversity of opinion on the cause of angina pectoris translated, and still does, into a diversity of treatment opportunities. Heberden himself said that he had little to offer apart from quiet, warmth, and spirituous liquors. He also noticed that opium, given in the evening, prevents attacks of angina during the night. The real first advance came in 1867 when Thomas Brunton suggested that amyl nitrite causes a relief of angina pectoris [21]. A few years later, in 1879, W.M. Morrell published in The Lancet the beneficial symptomatic effects of a solution of nitro-glycerine in alcohol given to 3 patients with angina pectoris [22]. James Black correctly understood that angina was often precipitated by emotion or exercise and set out to identify an inhibitor of the beta-receptor to treat angina: in 1965 propanolol became the first clinically available beta-receptor blocker [23]. In 1964, Albert Fleckenstein and his colleagues, while investigating the properties of 2 newly synthetized coronary dilators, prenylamine and verapamil, observed that, as well as producing the expected coronary dilator response, both compounds exerted a negative inotropic effect on the heart, which was counteracted by calcium. Thereafter, they concluded that their negative inotropic action is due to the ability of these drugs to block excitation-induced calcium influx, hence the genesis of the term "calcium channel blocker" or "calcium antagonists" [24]. Subsequently, these are now the 3 classes of drugs currently labelled by the guidelines as the first-choice treatment!

\section{Epidemiology and Prognosis of Angina}

What is meant by the term "angina pectoris" is difficult to define for a number of reasons. Randomized clinical trials do not necessarily reflect the real-life patient population. In registries, because of the multiform nature of stable angina, its prevalence and incidence vary according to the diagnostic criteria used. The diagnosis of angina is purely clinical and based on a number of subjective characteristics of pain such as quality, duration, site, and the precipitating or triggering factors. Moreover, angina is often synonymous with ischaemic heart disease - a terminology that embraces several different conditions, including patients with prior cardiovascular events, those who have already undergone percutaneous coronary intervention or surgical coronary artery bypass, as well as those who have evidence of silent myocardial infarction on the ECG, the 2D echocardiogram, and/or the different imaging modalities.

The prevalence of angina has changed over time, perhaps reflecting the high volume of interventional procedures performed, the aging of the population, and a better understanding of gender differences in the pathophysiology. It is estimated that the prevalence of angina in Western countries is $30,000-40,000$ cases per million [25]. The prevalence increases with age in both genders. Among 
Fig. 2. Etiology of chest pain without obstructive CAD. The varying pathophysiologic mechanisms of chest pain without obstructive $\mathrm{CAD}$ are grouped into 3 broad categories: non-cardiac, cardiac non-ischaemic, and cardiac ischaemic. Often single mechanisms overlap.

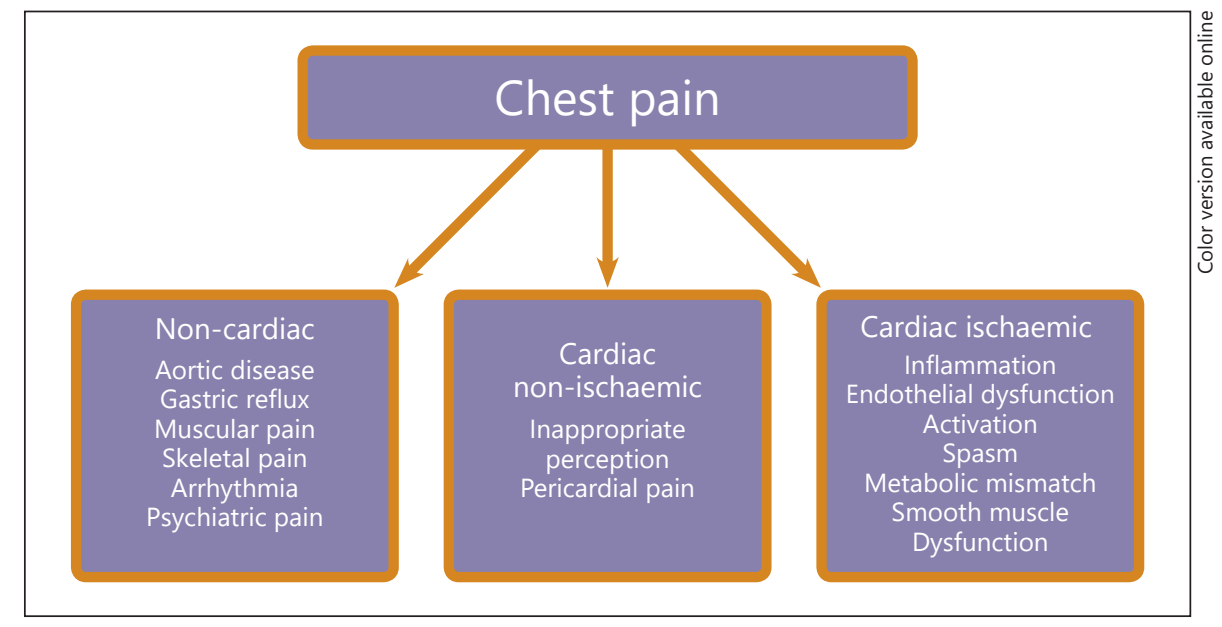

women, it is estimated to affect from 5-7\% aged 45-64 years to $10-12 \%$ aged $65-84$ years, and among men from $4-7 \%$ aged $45-64$ years to $15-14 \%$ aged $65-84$ years [1]. A meta-analysis on more than 25,000 angina cases in 31 countries showed that women have a slightly higher prevalence than men, independently by menopause, even with a lower rate of myocardial infarction [26]. Women have less obstructive CAD, but a higher prevalence of coronary microvascular dysfunction than men, as shown in the WISE (Women's Ischemia Syndrome Evaluation) study, [27]. Obesity, even if its rate is equal among men and women, is a more potent risk factor for angina in women than in men [28]. The main age of patients with angina is 65 years for men and 70 years for women, underlining, once again, the gender difference in the prevalence of disease [29].

Available data suggest an annual incidence of angina pectoris of $1 \%$ for the Western male population aged 45 65 years, with a slightly higher incidence in women. There are currently 4.1 million deaths due to CAD in Europe each year, with $82 \%$ of these deaths in people older than 65 years, and $46 \%$ in people older than 75 years [30]. The annual death rate of patients with stable angina is between 1.2 and $2.4 \%[1,2]$. The incidence and prevalence of patients with angina is anticipated to increase in the coming decade as a result of the aging of the population, the epidemic of obesity and other risk factors, the greater use of life-prolonging therapies, and the better management of acute coronary syndromes [30-33].

It is important to note that the available data on natural history and prognosis of angina do not take into consideration contemporary medical therapy, especially with angiotensin-converting enzyme inhibitors and statins (drugs that reduce mortality and morbidity in CAD). Therefore, it is likely that the prognosis is better than that reported in published data [34]. However, individual prognoses can vary considerably, depending on baseline clinical, functional, and anatomic characteristics. In the majority of patients, early manifestations of CAD include endothelial dysfunction and microvascular disease, and the overt epicardial stenosis develops and becomes symptomatic only after a variable length of time. The longterm prognosis is influenced by left ventricular systolic function, the extent of CAD, exercise duration or effort tolerance, and comorbidities.

The increasing use of an interventional approach for acute myocardial infarction and the higher adherence to medical therapy supported by guidelines resulted in a $33 \%$ reduction in cardiac deaths at 5 years after hospital discharge, but in a $57 \%$ increase in non-cardiac deaths in older and frail patients.

Angina affects society, as patients suffering from it have a reduced quality of life and impaired ability to perform daily activities, which may lead, in some cases, to retirement from work $[35,36]$. This comes at a high cost: in 2000 the cost of angina was estimated to be USD 8.9-15 billion [37]. Thus, angina remains a burden to health care systems and a clear understanding of the underlying pathophysiology is critical for its optimal management.

\section{Pathophysiology of Angina}

\section{Causes of Chest Pain}

Chest pain can have different causes and mechanisms, which are summarized in Figure 2. These are grouped 
into 3 broad categories: non-cardiac, cardiac non-ischaemic causes, and cardiac ischaemic causes. Causes of non-cardiac chest pain are gastro-oesophageal reflux disease, musculoskeletal alterations, pulmonary and aortic diseases, and psychiatric conditions. Causes of non-ischaemic cardiac pain are pericarditis and pericardial diseases. As for the cardiac ischaemic group, atherosclerotic disease of the epicardial coronary arteries has been accepted as the cause of angina pectoris for more than 2 centuries. Subsequently, spasm of epicardial coronary arteries was recognized as an adjunctive, functional mechanism of transient myocardial ischaemia and angina [9]. Furthermore, many patients undergo coronary angiography because of chest pain syndromes believed to be indicative of CAD. A significant proportion of these patients (up to 40\%), however, are found to have normal or, at least apparently normal, coronary arteries or non-obstructive CAD (stenosis $<50 \%$ ). For many years, there was uncertainty on the real significance of the anginal symptoms that are often accompanied by electrocardiographic evidence of ischaemia during stress. In the late 1980s, Epstein and Cannon [38] demonstrated that, compared to a group of asymptomatic controls, patients with chest pain and angiographically normal coronary arteries had heightened sensitivity of the coronary microcirculation to vasoconstrictor stimuli associated with a limited microvascular vasodilator capacity during atrial pacing, and termed this condition microvascular angina. They proposed that dysfunction of intramural small arteries and arterioles might be the cause of microvascular angina.

\section{Angina with Epicardial Coronary Disease}

Angina represents the clinical symptom of myocardial ischaemia which, in turn, occurs when the myocytes do not have enough oxygen for the mitochondrial oxidation, as a result of an imbalance between myocardial oxygen demand and delivery [39]. In the traditional view, angina symptoms can be precipitated by exercise or emotional stress-induced ischaemia in patients with atherosclerotic $\mathrm{CAD}$ in the large coronary arteries.

Several factors contribute to myocardial oxygen demand. The most important are: heart rate, blood pressure or afterload, myocardial wall tension, cardiac hypertrophy, and myocardial contractility. Conversely, the major determinants of oxygen delivery include coronary blood flow which, in turn, depends on the pressure gradient across the coronary circuit and the integrity of the coronary arteries, as well as from the oxygen-carrying capacity of the blood and the haemoglobin level.
The heart is extremely dependent on adequate oxygen delivery to allow the physiological production of energy (in the form of adenosine triphosphate; ATP) to support its contraction and basal metabolism. It has been calculated that, in a day, the human heart performs about 100,000 beats, pumps about 9,000 L of blood into the circulation, and uses a considerable amount of ATP (estimated to be between 16 and $30 \mathrm{~kg}$ ), which is produced by the mitochondrial oxidation of acetyl-coA and immediately utilized to allow contraction of the myofilaments in the systole and calcium extrusion in the diastole [40]. This explains the high number of mitochondria in the heart, the high capacity $(70-80 \%$ !) of the myocytes to extract oxygen from the arterial blood, and why the heart depends on oxygen delivery through the coronary arteries. Under physiological conditions, an increased demand of oxygen is met by an increase in coronary blood flow as a consequence of the dilation of coronary arteries, which does not occur in patients with atherosclerotic lesions of the epicardial coronary artery.

From a metabolic point of view, myocardial ischaemia results in anaerobic glycolysis with a consequent increased concentration and release of $\mathrm{H}^{+}, \mathrm{K}^{+}$, and lactate in the venous blood draining the ischaemic territory. The resulting acidosis compete with calcium ions and freeze all movements through the sarcolemma and sarcoplasmic reticulum, thus causing the well-known "ischaemia - induced regional hypokinesia or akinesia" [41]. In the clinic, existence of metabolic ischaemia is documented by a drop of $\mathrm{pH}$ in the venous coronary sinus blood concomitant with a release of lactate from the ischaemic myocytes, causing inversion of the percentage of myocardial arterial venous difference of lactate, which changes from positive to negative [42]. These biochemical alterations precede the actual occurrence of the classical ECG changes and of the chest pain, as well as the regional alteration of contractility (Fig. 3). It is important to emphasize that in patients with angina these changes are transient and, normally, require a trigger (i.e., exercise, stress, exposure to cool temperature, etc.) which creates the metabolic mismatch. The ultimate cause of pain is controversial, as angina pain is complex in its quality, and has a rather chaotic association with ischaemia. In the heart, several $\alpha$-ganglia are present, mainly in the epicardial fat, and are supplied by proximal coronary arteries. Both afferent and efferent neurons integrate not only with intrinsic cardiac neurons, but also with the mediastinal, cervical, dorsal, and stellate ganglia, explaining why pain can be felt in different parts of the body, although it most frequently occurs in the chest and/or left arm [43]. 
Adenosine, like many other mediators, is released in large quantities during myocardial ischaemia in the interstitial space and, through the adenosine A1 receptors, modulates the activities of the efferent neurons, thus causing pain [43]. When given intravenously to volunteers or patients with ischaemic heart disease, adenosine provokes angina-like pain and therefore is considered to be the cause of angina pain. Taken together, current evidence suggests that pain is mainly caused by the stimulation of chemoreceptors by adenosine released into the myocardium during ischaemia projecting to the specific cortical area [44].

\section{Angina without Epicardial Coronary Artery}

\section{Obstruction}

The notion that angina is caused by epicardial stenosis limiting coronary flow reserve, first described by Gould and Lipscomb [6] and later by Braunwald and Sobel [45], remains true for the majority of patients, as demonstrated by the efficacy of percutaneous coronary angioplasty to improve angina [46]. The concept, however, has been challenged on the basis of different observations. In a fraction of patients, myocardial ischaemia can persist or re-occur after having undergone successful coronary revascularization $[47,48]$. These disappointing results have been attributed to a number of factors, such as incomplete revascularization, in-stent restenosis, and, importantly, patient-related factors. However, even when all possible confounding factors have been excluded, one-third of patients remain symptomatic with a positive exercise test, within 1 day after successful revascularization [49]. Outcome analyses show little or no prognostic impact of elective angioplasty [50]. It is accepted that there is no significant difference in all-cause mortality between patients with stable angina treated with medical therapy and those treated with coronary revascularization by angioplasty [50-52]. Autopsy studies of patients with angina also support the notion that coronary artery obstruction is not necessarily synonymous of myocardial ischaemia [53]. Even patients with acute coronary syndrome and angiographic and electrocardiographic evidence of ischaemia can have normal coronary arteries at autopsy [54]. Recently, the pathophysiological relevance of obstructive lesions in the genesis of myocardial ischaemia and its related symptoms has been further elucidated by the possibility to measure the link between the degree of coronary stenosis and the actual tissue perfusion and, therefore, the likelihood of the occurrence of ischaemia by the fractional flow reserve technique. Indeed, fractional flow reserve measurements have shown that not all epicardial athero-

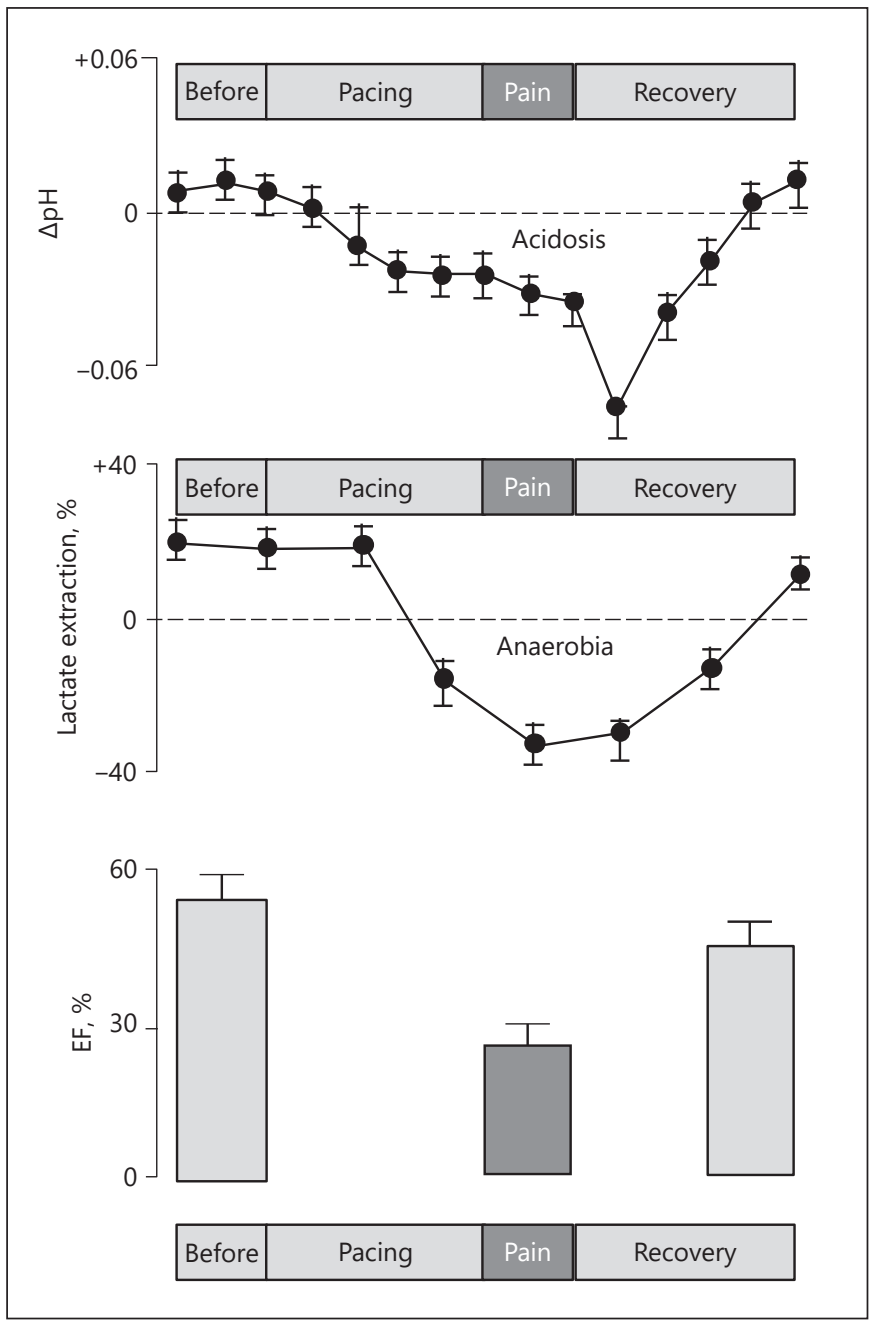

Fig. 3. Metabolic changes during the early phases of ischemia in a patient with CAD subjected to atrial pacing. $\Delta \mathrm{pH}$, continuous $\mathrm{pH}$ measured in the coronary sinus by a $\mathrm{Ph}$ electrode; lactate extraction, concentration of arterial lactate - coronary sinus concentration normalized for the arterial level; EF, ejection fraction.

sclerotic lesions necessarily result in a level of myocardial ischaemia to justify symptom-suggested angioplasty [55].

Thus, it seems that a sizeable proportion of patients with evidence of myocardial ischaemia do not show obstructive coronary atherosclerosis at coronary angiography. Conversely, some patients with severe coronary atherosclerotic obstructions do not show evidence of ischaemia and do not experience chest pain. These and other observations have led to the idea that angina may also be present in the absence of obstructive coronary atherosclerosis and may persist after the treatment of epicardial stenosis. These patients are not only a diagnostic and thera- 
peutic challenge, but contribute to significant economic, social, and health cost $[8,10]$.

In a subset of patients with angina and normal coronary arteries, the symptoms may be due to hypertension, severe aortic stenosis, anaemia, supraventricular tachycardia, hypertrophic cardiomyopathy, congenital coronary anomalies, or a myocardial muscle bridge. All these conditions and/or comorbidities account for a diminished coronary flow reserve, thus resulting in myocardial ischaemia.

Another circumstance in which the coronary arteries might present a normal result at coronary angiography is so-called vasospastic angina [56]. This condition occurs in a minority of patients, it is due to an abnormal reactivity of the smooth muscles of the coronary arteries (which, therefore, cannot be considered functionally normal). This form of angina is referred to as vasospastic angina and presents with specific characteristics, i.e., pain is not triggered by exercise, but occurs at rest. Vasospasm can be evoked by different triggers and requires specific diagnostic tests and therapies, as will be discussed later [56]. A certain degree of coronary spasm might also be superimposed to a non-occlusive fixed atherosclerotic stenosis, which becomes occlusive, and therefore symptomatic when the smooth muscle constricts.

In the majority of patients with angina and normal or near-normal epicardial coronary arteries, the angina is caused by coronary microvascular dysfunction responsible for microvascular angina, previously known as cardiac syndrome $\mathrm{X}$ [57]. The latter most often pertains to women with symptoms of angina, normal or near-normal coronary arteries, and evidence of ischaemia during stress testing or during acetylcholine testing [58].

Recently, more and more attention has been devoted to the recognition of this condition and it is estimated that microvascular angina could occur in up to $40 \%$ or even more, depending on the study consulted [59-61]. This high percentage, however, includes patients with symptoms of angina with suspected ischaemia, but without a clear demonstration of it. The prognosis is not benign, as previously thought, and these patients are at risk of major adverse cardiovascular events, including cardiac death, stroke, myocardial infarction, and heart failure, particularly cardiac failure with preserved ejection fraction $[62$, 63]. A new paradigm is emerging from autopsy specimens of subjects with heart failure and preserved ejection fraction, which suggests an association between abnormal microvascular density and left ventricular fibrosis, the marker of heart failure with preserved ejection fraction [64-66].

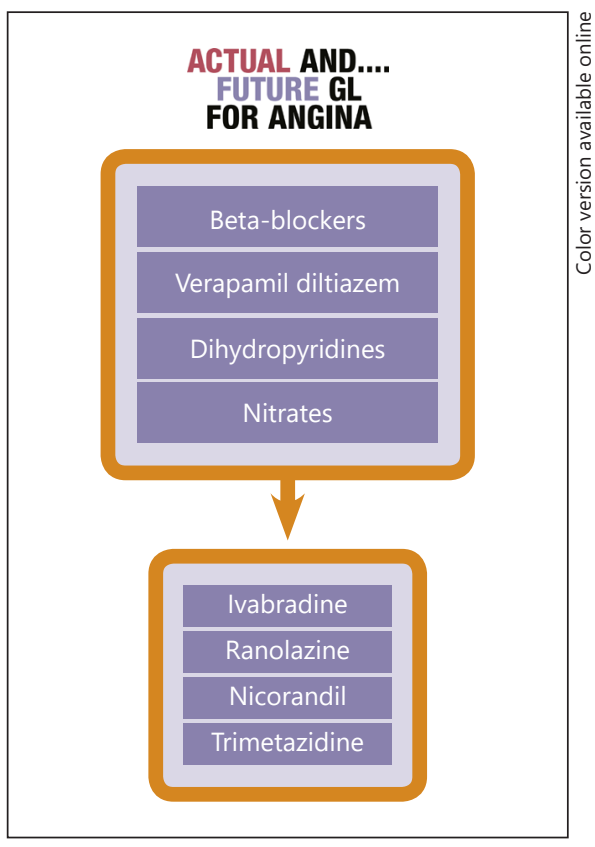

Fig. 4. Different manifestations of myocardial ischaemia. Hierarchical algorithm of the antianginal drugs.

Pathogenesis of Coronary Microvascular Dysfunction

Excellent reviews have been published on the pathophysiology of coronary microcirculation, to which the reader is referred [67-70]. All, however, suffer from a lack of consensus on definitions, mechanisms, clinical manifestations, diagnosis, and effective treatment strategies. We will briefly summarize the proposed hypothesis as these are relevant to the symptomatic treatment of angina.

There are several hypotheses for the pathophysiology of coronary microvascular dysfunction [67]. Perhaps the most accepted one is a dysfunction of the endothelial cells of the microvascular network (Fig. 4). It is known that under physiological conditions the endothelium produces a number of mediators with vasorelaxing, antiproliferative, anti-apoptotic, and antithrombotic effects. In addition, endothelial cells also regulate the contractile function of cardiomyocytes by influencing the activity of the gap junction [67]. The cause of endothelium dysfunction seems to be linked to increased oxidative stress with consequent release of thromboxane A2, prostaglandin $\mathrm{H} 2$, and superoxide, thus converting the dilator response to different stimuli into a constrictive response. Endothelium dysfunction also activates inflammatory responses with the expression of chemokine and adhesion mole-
Balla/Pavasini/Ferrari 
cules which, in turn, affect the microcirculation [71]. In the presence of coronary endothelial dysfunction, responses to $\alpha$-adrenergic activation is augmented, causing vasoconstriction of the microvessels, able to induce myocardial ischaemia. Against this hypothesis, however, is the finding that the efficacy of $\alpha$-adrenergic antagonists is, at best, uncertain [72].

Clinically, endothelium function can be tested with different methods, the most frequently used being intravascular administration of acetylcholine to evoke nitric oxide-dependent vasodilation. In patients with a diagnosis of microvascular angina, a reduced flow increase in response to acetylcholine, despite a normal increase in the diameter of epicardial coronary arteries, has been documented [73]. Structural abnormalities responsible for coronary microvascular dysfunction have been consistently documented, particularly in patients with arterial hypertension. Morphologic changes are characterized by adverse remodelling of intramural coronary arterioles resulting in medial wall thickening, mainly due to smooth muscle hypertrophy and increased collagen deposition, with variable degrees of intimal thickening. This is the anatomical substrate underlying the abnormal coronary physiology and blood flow in these patients [74]. During the cardiac cycle, the pulsatile pattern of coronary blood flow follows physiologic variations, which are influenced by the changes in intramyocardial and intraventricular pressures, occurring during the systole and diastole [75]. Since flow mainly occurs in the diastole, abnormalities in this phase of cycle affect myocardial perfusion to a larger extent. However, an increase in systolic intramyocardial and ventricular pressures, as typically occurs in primary and secondary left ventricular hypertrophy, may negatively impact on myocardial perfusion [74, 76]. Another interesting hypothesis relates to the existence of an altered mismatch between metabolic signalling and microvascular adaptation. It is well known that, in a condition of increased oxygen demand, metabolic signalling evokes several mediators able to increase blood flow [77]. In case of a mismatch of this complex signalling chain, the result will be a heterogeneity of spatial perfusion at rest and a reduced vasodilation when the demand increases, i.e., during physical exercise or stress [78]. It follows that the pathophysiological mechanisms of coronary microvascular dysfunction are multiple and may act alone or in combination.

The clinical diagnosis of microvascular angina remains difficult. The dynamic development of new imaging modalities, both invasive and non-invasive, has certainly contributed to establish the relevance of coronary

Treatment of Angina: Where Are We? microvascular alterations but has not yet produced a validated diagnostic test, as the in vivo visualization of the human microcirculation is not possible at present [59]. The most used approaches, at the moment, are the evaluation of coronary reactivity to acetylcholine and assessment of the coronary flow reserve and myocardial perfusion reserve using position emission tomography or cardiac magnetic resonance imaging. However, even with these sophisticated techniques, the threshold for defining dysfunction differs between studies [59]. The lack of a standardized definition and diagnostic criteria has made the evaluation of treatment strategies for microvascular angina challenging. The current approach is to use traditional antianginal and risk-reduction therapies targeted at epicardial CAD. However, this seems not to be effective in the management of coronary microvascular dysfunction, particularly those treatments suggested as being first choice by the guidelines.

In summary, it is not easy to diagnose angina and its multiple causes. A careful history remains the cornerstone for the diagnosis of chest pain and objective tests are often necessary to prove myocardial ischaemia and, therefore, confirm the diagnosis. Traditionally, and not very differently from Heberden's description, typical angina should meet all of the following criteria: (a) typical chest pain in terms of quality and duration, (b) it should be provoked by exertion or emotional stress, and (c) it should be relieved by rest and/or nitrates within minutes. When the pain meets only 2 of these criteria, it should be considered probable, and when it meets only 1 of the criteria, it should be considered very unlikely [1].

\section{Pharmacological Treatment of Angina}

In patients with stable $\mathrm{CAD}$, anti-ischaemic therapy should fulfill 2 major goals: (1) safely alleviate symptoms, extend exercise duration, and improve quality of life, and (2) improve prognosis, preventing CV events, mainly myocardial infarction and cardiovascular death, by reducing the incidence of acute coronary thrombosis and slowing the progression of coronary atherosclerosis and the development of ventricular dysfunction. Unfortunately, drugs recommended by standard guidelines both as the first- and second-line treatment do not alter the risk of disease progression, frequency of myocardial infarction, cardiac death, or all-cause mortality [1-4]. Conversely, pharmacological therapy to prevent $\mathrm{CV}$ events with aspirin, statins, and angiotensin-converting enzyme inhibitors do not reduce angina. This distinction of drugs to improve prognosis and 


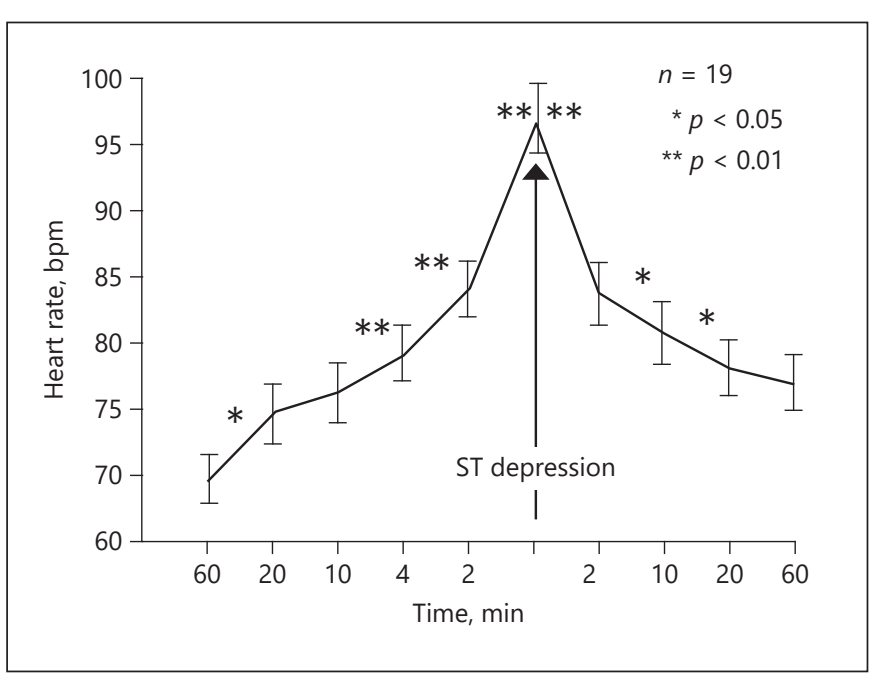

Fig. 5. Change in heart rate $1 \mathrm{~h}$ before and after an ischaemic event.

those relieving symptoms is clearly evident in the most important guidelines. Whilst there is abundant data from clinical trials to support the use of drugs aimed to improve prognosis, there is a paucity of data to support the differentiation of antianginal drugs in the first and second line of treatment [14-18]. As Figure 4 shows, the majority of guidelines, and certainly those of the ESC, consider sublingual or short-acting nitro-glycerine, beta-blockers, and calcium channel blockers as first-choice therapy, whilst the other more recent drugs (ivabradine, nicorandil, ranolazine, and trimetazidine) are reserved for patients who have contraindications to the first-choice drugs, or who fail to tolerate them, or who remain asymptomatic. These drugs are labelled as second-choice treatment despite their similar objectives and more contemporary data being available for them than for the first-choice drugs [14-18].

The use of these drugs are recognized by the ESC guidelines. It should be noted that ivabradine, nicorandil, and trimetazidine are not mentioned in the American and Canadian guidelines as these drugs are not available in the USA or Canada. This is partially true for ivabradine which is actually marketed in the USA for the treatment of heart failure and, as shown by a subanalysis of the SHIFT trial, patients with angina and heart failure might benefit from the concomitant use of ivabradine [79]. Ranolazine is also not mentioned in the Canadian guidelines. In the AHA/ACC guidelines, ranolazine is recommended as a class IIA indication when used in combination with beta-blockers and IIB when used as the first-line treatment, when contraindications exist for the first rec- ommended line of medications [2]. Other relevant differences between the ESC and AHA/ACC guidelines relate to beta-blockers. The ESC experts suggest the chronic use of beta-blockers in patients with documented large areas of ischaemia and ventricular dysfunction, while in the AHA/ACC guidelines, beta-blockers are suggested as chronic treatment for all patients with $\mathrm{CAD}$ independently from the ventricular dysfunction or not.

Despite these and other minor differences, the common approach of the ESC, NICE, and AHA/ACC guidelines is the classification of drugs into the first and second line. However, there are no head-to-head comparisons between first- and second-line treatments that demonstrate a superiority of one versus the other in terms of antianginal effects. Furthermore, double and sometimes triple therapy with different classes of antianginal drugs is often needed and the actual guidelines do not provide an indication of the best possible combination. That is the reason why a sort of "diamond approach" (Fig. 1) has recently been proposed [18]. This approach seems useful and logical as it allows a more individualized treatment according to the patient's characteristics, comorbidities, and underlying pathologies. It is clear from the literature that, when compared with each other, some agents, beside the antianginal effect, possess specific properties which allow the identification of the best treatment for the specific physiopathology or for the co-existing comorbidities and/or risk factors.

\section{Pharmacological Therapies for Angina}

Traditionally, drug treatment for angina focused on improving the balance between myocardial oxygen delivery and consumption through heart rate and blood pressure or afterload reduction and enhancement of coronary flow by vascular (coronary) muscle relaxation. Heart rate is the major determinant of oxygen consumption, and most attacks of angina are preceded by an increase of heart rate, as shown by ECG Holter monitoring (Fig. 5). it is not surprising that heart rate reduction improves angina and heart rate modulators are the most used antianginal agents.

\section{Drugs That Reduce Heart Rate}

There are 3 classes of drugs that reduce heart rate: beta-blockers, ivabradine, and non-dihydropyridine calcium antagonists, mainly verapamil and diltiazem.
Balla/Pavasini/Ferrari 


\section{Beta-Blockers}

In patients with angina, beta-blockade reduces the burden of ischaemia by slowing the heart rate at rest and during exercise. In addition, beta-blockers reduce myocardial contractility and blood pressure, with both effects contributing to reduce oxygen demand. By reducing the heart rate, diastolic time increases and, consequently, coronary perfusion also ameliorates, thus improving oxygen supply. There are other indirect effects of beta-blockers, mainly related to contrasting to the deleterious effects of catecholamines, but the main antianginal action is related to heart rate reduction. Beta-blockers have several side effects [80], including bradycardia, hypotension, bronchospasm, fatigue, and blunting of the tachycardia response to hypoglycaemia, leading to postural hypotension. These side effects are less evident in $\beta_{1}$-selective beta-blockers, such as metoprolol, atenolol, and especially bisoprolol. Other agents are selective for the $\beta_{1}$-receptors and also possesses $\alpha$-blocking activity, resulting in vasodilation. These are labetalol and carvedilol. Finally, nebivolol is a selective $\beta_{1}$-antagonist with vasodilatory effects through nitric oxide production [81]. For this reason, nebivolol is approved by the Food and Drug Administration for hypertension. A considerable proportion of patients with CAD are intolerant to beta-blockers or encounter side effects (especially fatigue) which further limit their use. In these cases, if the heart rate remains elevated, it is recommended to use ivabradine either alone or in combination [82].

\section{Ivabradine}

Ivabradine exerts its action through the inhibition of the so-called "If channel," where "f" means funny [83]. These channels are located in the sinus node atrial cell. By inhibiting the $I_{\mathrm{f}}$ current, ivabradine reduces the slope of the slow diastolic depolarization phase of the action potential in the sinus node cells, thereby selectively reducing heart rate. It follows that ivabradine's mechanism of action is complementary to that of beta-blockers. The effects of ivabradine are "use dependent" as it binds preferentially to the channels that are in the open state. It follows that the effects of ivabradine on heart rate is greater when the heart rate is high and lower when the initial heart rate is low [84]. Furthermore, in contrast to betablockers and to non-dihydropyridines calcium antagonists, ivabradine has no negative inotropic or lusitropic effects. Recently, ivabradine has also been shown to increase coronary collateral perfusion and the coronary flow reserve [85-87]. In addition, ivabradine does not unmask $\alpha$-adrenergic vasoconstriction and, unlike beta-

Treatment of Angina: Where Are We? blockers, it maintains the physiological coronary dilation during exercise. For all these reasons, ivabradine should be added to beta-blockers any time the heart rate remains elevated. There are several clinical data in support of this concept. In the ASSOCIATE trial, ivabradine added to atenolol further and safely improved exercise tolerance in subjects with stable angina [88]. In another study in patients with refractory angina despite treatment with betablockers, when added to bisoprolol, ivabradine significantly further improved exercise tolerance more than doubling the dose of bisoprolol [82].

A recent analysis of patients with ischaemic heart disease and angina enrolled in SHIFT showed that the outcome benefits of ivabradine were maintained [79]. The "morbidity mortality evaluation of the $l_{\mathrm{f}}$ inhibitor ivabradine in patients with CAD and left ventricular dysfunction" (BEAUTIFUL) trial, involving 10,917 patients with stable CAD and left ventricular dysfunction, assessed the effects of ivabradine on patient outcomes [89]. The primary endpoint was not improved by ivabradine. In a prespecified subgroup of patients with heart rates $\geq 70 \mathrm{bpm}$ or in patients with angina at entry, ivabradine reduced the rate of myocardial infarction [90]. These data need to be considered with great caution, as they are the results of a subgroup analysis of a neutral trial. In the SIGNIFY trial, when added to guideline-recommended therapy with beta-blockers, ivabradine did not affect outcomes but improved symptoms of angina and quality of life [91].

\section{Verapamil and Diltiazem}

Other drugs able to reduce heart rate are the non-dihydropyridines, calcium channel blockers, verapamil, and diltiazem. Both these molecules are less selective for the calcium channels in the vasculature than the classical dihydropyridines (nifedipine, amlodipine, felodipine, and nisoldipine).

As a consequence, verapamil and diltiazem have more pronounced effects on calcium channels of the myocytes as well as of the cardiac pacemaker and atrioventricular conduction cells, leading to a negative inotropic effect and reduction of heart rate. It follows that the antianginal action is more balanced than that of dihydropyridines, although with similar efficacy. Owing to their intrinsic negative inotropic effects, verapamil and diltiazem, in addition to the usual side effects of the other calcium-channel blockers, might reduce ventricular contractility and cause constipation. Furthermore, these 2 drugs suppress cardiac contraction; therefore, in susceptible patients, they might lead to unwanted bradycardia. As a conse- 
quence, they should be used with great caution in combination with other drugs that affect heart rate, such as beta-blockers. For this reason, in the diamond scheme of Figure 1, the line for the combination of beta-blockers or ivabradine with verapamil or diltiazem is red. Verapamil and diltiazem are metabolized in the liver to a less active metabolite by cytochrome P-450 CYP3A4, which also metabolizes ivabradine. It follows that it should never be combined with ivabradine due to the risk of severe bradycardia. In the SIGNIfY trial, although this combination was clearly discouraged, $4.6 \%$ of the patients were treated with verapamil and diltiazem, and this might have contributed to excess bradycardia and the worsening of outcomes [91].

Verapamil and diltiazem should not be used in patients with angina and left ventricular dysfunction and/or heart failure as they might have deleterious effects on outcomes [92]. In this particular subset of patients, when the heart rate is elevated ( $\geq 70 \mathrm{bpm})$, beta-blockers and ivabradine are the preferred drugs.

\section{Drugs That Induce Vascular Smooth Muscle Relaxation}

Three classes of drugs exert their main effects by primarily reducing vascular smooth resistance and, consequently, cause arteriolar and coronary artery dilatation: these are dihydropyridine calcium channel blockers, nitrates, and nicorandil.

\section{Dihydropyridine Calcium Channel Blockers}

Calcium channel blockers are classified, according to their structure, as dihydropyridines or non-dihydropyridines. All of them (the dihydropyridines in particular) inhibit calcium influx through the high-voltage-activated L-type calcium channel, located in the smooth muscle of the arterial wall, leading to smooth muscle relaxation [93]. Dihydropyridines have high selectivity and affinity for L-type channels of the vasculature with a decrease of coronary and systemic vascular resistance. It follows that they reduce cardiac afterload and, therefore, oxygen need and improve oxygen delivery by improving coronary dilatation. A reflex tachycardia might occur after administration of dihydropyridines calcium blockers. In this case, a concomitant use of a beta-blocker might be useful to blunt the reflex and allow an additional anti-ischaemic effect [94].

The non-dihydropyridines, such as verapamil and diltiazem, are less selective and also act on calcium channels of the myocytes and of the pacemaker and atrioventricular conduction cells, and have already been described.

While all calcium channel blockers are effective in the treatment of vasospastic angina and improve symptoms of "classic" angina [95], none of them improve the survival of patients with angina with or without myocardial infarction or left ventricular dysfunction [96]. There is no indication to use them in microvascular angina as, surprisingly, they have been shown to have no effect on microvascular dysfunction [97].

\section{Nitrates}

Nitrates exert their effect primarily by the relaxation of vascular smooth muscle. In the vessel wall, they undergo enzymatic denitrification by mitochondrial aldehyde dehydrogenase, thus producing nitric oxide, which in turn stimulates cyclic guanylate cyclase and, consequently, vasodilatation [98]. At low doses, nitrates are predominantly venodilators, thus reducing preload and venous return, whilst at higher doses nitrates also dilate peripheral coronary arteries with a consequent reduction of afterload and myocardial oxygen demand. As with dihydropyridines, the effects on pre- and afterload are often partly offset by an increase of heart rate and myocardial contractility due to reflex sympathetic activity. Thus, combining nitrates with beta-blockers and ivabradine might be useful to block tachycardia. Nitrates improve angina symptoms, but this class is ineffective in improving quality of life due to the risk of adverse events, which include headache, flushing, palpitations, and hypotension [99].

Short-acting nitrate preparations (such as sublingual and trans-oral sprays or nitro-glycerine patches) are rapidly absorbed and very effective in angina relief. These are considered the drugs of choice during acute angina pectoris, while long-acting preparations are used for prophylaxis of angina [100]. However, long-acting nitrates face the problem of tolerance: particularly when used 3 or 4 times a day, there is a marked attenuation of the haemodynamic and antianginal effects as a result of exhaustion of the nitric oxide pool at the membrane level of the vessel wall.

\section{Nicorandil}

Nicorandil is a nitrate derivative of nicotinamide and an adenosine-sensitive potassium channel opener with nitric oxide donor capacity, thus resulting in the dilatation of the coronary arteries with an increase of myocardial blood flow [101]. As a consequence of its capacity to open the ATP-sensitive potassium channels, it also exerts a sort of preconditioning on the myocardium [102]. In a
Balla/Pavasini/Ferrari 
large, multicentric, controlled, outcome study (IONA; the impact of nicorandil in angina) nicorandil reduced the composite of $\mathrm{CV}$ death, non-fatal myocardial infarction, or unplanned hospital admission for cardiac pain at a median of 1.6 years compared with placebo, despite $39 \%$ of patients withdrawing in the treated group because of headache [103]. Cardiovascular mortality was not reduced and the beneficial effects were mostly driven by hospitalization for unstable angina [103]. In a propensity score-matched analysis of 5,116 Japanese patients with CAD, nicorandil reduced the frequency of angina attacks compared to sustained release nitro-glycerine [81]. Another currently ongoing trial in China is testing nicorandil on the background of standard therapy in patients with stable angina [6]. Nicorandil is approved for the treatment of angina in Japan, France, Iran, Lebanon, and the UK.

\section{Metabolic Modulators and Late Sodium Current Inhibitor}

Drugs that belong to this class are piperazine derivatives. At present, 2 agents are clinically available: trimetazidine and ranolazine.

\section{Trimetazidine}

Although the exact mechanism of the antianginal effect of trimetazidine is not known, in experimental preparation it increases cellular tolerance to ischaemia by inhibiting the mitochondrial long-chain ketoacyl coenzyme A thiolase and, consequently, increases the anaerobic glucose metabolism. Trimetazidine directs pyruvate into the mitochondria, this maintains the flow of glucose to pyruvate in the cytosol and, in turn, causes less production of lactic acid and protons form the acutely ischaemic myocytes. The net consequences of the trimetazidine effect on cardiac substrates are a reduction of FFA acids oxidation and an increase of anaerobic glucose utilization by the ischaemic myocardium with less production of protons and lactic acid production (less acidosis) and more anaerobic ATP production from the cytosol [104]. These metabolic changes have been confirmed in clinical settings, where trimetazidine did increase myocardial levels of high-energy phosphates in patients with heart failure [105]. In a meta-analysis of 23 randomized trials, trimetazidine improved angina symptoms compared with placebo or other antianginal therapies [106]. In a Cochrane meta-analysis, the antianginal effects of trimetazidine were similar to those of other antianginal

Treatment of Angina: Where Are We? agents [107]. A large multicentric clinical trial involving over 6,000 patients, the "randomized, double-blind, placebo-controlled trial to assess the efficacy and safety of trimetazidine in patients with angina pectoris having been treated by percutaneous coronary intervention" (ATPCI study), is currently ongoing. The study aims to establish the effects of trimetazidine in patients after percutaneous coronary angioplasty treated with evidencebased standard therapy on a composite endpoint of CV death, hospitalization, and further antianginal treatment. Not surprisingly, in view of its mechanism of action, which is independent from a reduction or an improvement of the heart oxygen balance, the antianginal efficacy of trimetazidine has been confirmed in small studies on patients with a history of myocardial infarction [108], those with diabetes [109], and those with left ventricular dysfunction [110].

\section{Ranolazine}

Ranolazine is an active piperazine derivative that is structurally related to trimetazidine [111]. Like trimetazidine, the exact mechanism of action of ranolazine has not been fully elucidated. Beside the similar metabolic effects of trimetazidine, it has been shown that ranolazine causes a concentration, voltage, and frequency-dependent inhibition of the late sodium current, thus preventing intracellular calcium overload during ischaemia, resulting in the distribution of myocardial blood flow toward the ischaemic areas with a reduction of ischaemia [111]. Several large randomized trials have demonstrated that ranolazine, either as monotherapy or as an adjunctive to another antianginal drug, improves symptoms and increases exercise tolerance [111]. Ranolazine does not improve the outcome of patients with angina independently form the ventricular function. A recent large, randomized, multicentre trial found a lack of benefits of ranolazine in reducing the risk of urgent revascularization or hospitalization with unstable angina in subjects with incomplete revascularization after percutaneous coronary intervention [112]. Equally, non-beneficial effects in terms of outcome were found in the metabolic efficiency with ranolazine for less ischaemia in non-ST-elevation acute coronary syndromes (MERLIN) trial [113]. However, in the MERLIN trial, ranolazine significantly reduced $\mathrm{HbAlc}$, suggesting that diabetic patients with angina could benefit from ranolazine treatment. Equally, ranolazine is expected to be particularly effective in patients with angina and left ventricular hypertrophy. Following small positive proof of concept studies, another trial was conducted in patients with angina without epi- 
cardial coronary disease [114]. The results failed to show a superiority of ranolazine compared to placebo on the frequency of angina or a reduction of photon emission computed tomography-determined myocardial ischaemia. Finally, in contrast to all the other antianginal drugs, trimetazidine and ranolazine do not exert any chronotropic or inotropic effects.

\section{Conclusions}

Angina remains a major concern, and a remarkable proportion of patients continue to be symptomatic despite traditional pharmacological therapies. Among the investigational drugs currently under evaluation, there is an interest in older agents and on anti-inflammatory agents. Actually, recent data on canakinumab indicates that inflammation at the level of the coronary artery is one of the causes of coronary atherosclerosis progression towards myocardial infarction and CV death.

Among the various traditional therapies, beta-blockers, nitrates, and calcium blockers remain the most extensively used and, therefore, are considered as first-line agents in the guidelines. All these drugs provide symptomatic relief, with no benefits on hard outcomes. Other so-called second-line agents (i.e., ivabradine, ranolazine, trimetazidine) have been studied extensively and have more evidence-based clinical data that are more contemporary than those available for the traditional first-choice drugs. In addition, current guidelines do not really take into consideration the difference underlying the pathophysiology of angina, i.e., macrovascular versus microvascular or vasospastic angina.

Since all antianginal drugs possess a similar efficacy and level of evidence and no survival benefit, it is currently difficult to consider some drugs as first choice ahead of the others. Furthermore, patients with stable ischaemic heart disease and angina may have several comorbidities, and cardiac ischaemic pain might result from different underlying pathophysiologies. It is also clear that some agents, beside the antianginal effect, possess auxiliary properties which could be useful depending on the mechanisms of angina and co-existing comorbidities.

We believe it is time to consider a different, more individualized approach, with the patient and their comorbidities and mechanisms of angina at the centre. Recently, as with antihypertensive drugs, a "diamond approach" has been proposed [18]. This surpasses the current classifications into first and second lines, and we support this idea.

\section{Acknowledgements}

This work was supported by a grant from Fondazione Anna Maria Sechi per il Cuore (FASC), Italy.

\section{Conflict of Interest}

The funders had no role in the study design, data collection and analysis, decision to publish, or the preparation of the manuscript. R.F. has received honoraria for steering committee membership and consulting from Novartis and Servier, and for speaking and support for travel to study meetings from Merck Serono and Servier. The other authors have no conflicts of interest.

\section{Author Contributions}

All authors contributed to researching data, discussion of content, and reviewing and editing the manuscript before submission. R.F. wrote the manuscript.

\section{References}

1 Task Force Members, Montalescot G, Sechtem U, et al: 2013 ESC guidelines on the management of stable coronary artery disease: the task force on the management of stable coronary artery disease of the European Society of Cardiology. Eur Heart J 2013:34:2949-3003.

- 2 Fihn SD, Gardin JM, Abrams J, et al: 2012 ACCF/AHA/ACP/AATS/PCNA/SCAI/STS guideline for the diagnosis and management of patients with stable ischemic heart disease: a report of the American College of Cardiology Foundation/American Heart Association Task Force on Practice Guidelines, and the
American College of Physicians, American Association for Thoracic Surgery, Preventive Cardiovascular Nurses Association, Society for Cardiovascular Angiography and Interventions, and Society of Thoracic Surgeons. J Am Coll Cardiol 2012;60:e44-e164.

-3 Mancini GB, Gosselin G, Chow B, et al: Canadian Cardiovascular Society guidelines for the diagnosis and management of stable ischemic heart disease. Can J Cardiol 2014;30: 837-849.

4 National Clinical Guidelines Centre: Stable angina: full guideline: methods, evidence and guidance. 2011. http://www.nice.org.uk/ guidance/cg126/evidence/full-guideline183176605 (accessed Dec 9, 2015).

5 Abrams J: Clinical practice: chronic stable angina. N Engl J Med 2005;352:2524-2533.

6 Gould KL, Lipscomb K: Effects of coronary stenoses on coronary flow reserve and resistance. Am J Cardiol 1974;34:48-55.

-7 Paul TK, Sivanesan K, Schulman-Marcus J: Sex differences in nonobstructive coronary artery disease: recent insights and substantial knowledge gaps. Trends Cardiovasc Med 2016;27:173-179. 
-8 Marzilli M, Merz CN, Boden WE, Bonow RO, Capozza PG, Chilian WM, DeMaria AN, Guarini G, Huqi A, Morrone D, Patel MR, Weintraub WS: Obstructive coronary atherosclerosis and ischemic heart disease: an elusive link! J Am Coll Cardiol 2012;60:951-956.

-9 Lanza GA, Careri G, Crea F: Mechanisms of coronary artery spasm. Circulation 2011;124: 1774-1782.

10 Crea F, Camici PG, Bairey Merz CN: Coronary microvascular dysfunction: an update. Eur Heart J 2014;35:1101-1111.

-11 Sedlak T, Izadnegahdar M, Humphries KH, Bairey Merz CN: Sex-specific factors in microvascular angina. Can J Cardiol 2014;30: 747-755.

12 Coronary Artery Surgery Study (CASS): A randomized trial of coronary artery bypass surgery: survival data. Circulation 1983;68: 939-950.

13 Stergiopoulos K, Boden WE, Hartigan P, Möbius-Winkler S, Hambrecht R, Hueb W, Hardison RM, Abbott JD, Brown DL: Percutaneous coronary intervention outcomes in patients with stable obstructive coronary artery disease and myocardial ischemia: a collaborative meta-analysis of contemporary randomized clinical trials. JAMA Intern Med 2014;174:232-240.

14 Ridker PM, Everett BM, Thuren T, MacFadyen JG, Chang WH, Ballantyne C, Fonseca F, Nicolau J, Koenig W, Anker SD, Kastelein JJP, Cornel JH, Pais P, Pella D, Genest J, Cifkova R, Lorenzatti A, Forster T, Kobalava Z, Vida-Simiti L, Flather M, Shimokawa H, Ogawa H, Dellborg M, Rossi PRF, Troquay RPT, Libby P, Glynn RJ; CANTOS Trial Group: Antiinflammatory therapy with canakinumab for atherosclerotic disease. $\mathrm{N}$ Engl J Med 2017;377:1119-1131.

15 Thadani U: Management of stable angina current guidelines: a critical appraisal. Cardiovasc Drugs Ther 2016;30:419-426.

16 Camm AJ, Manolis A, Ambrosio G, et al: Unresolved issues in the management of chronic stable angina. Int J Cardiol 2015;201:200-207.

$\checkmark 17$ Ambrosio G, Komajda M, Mugelli A, et al: Management of stable angina: a commentary on the European Society of Cardiology guidelines. Eur J Prev Cardiol 2016;23:1401-1412.

18 Ferrari R, Camici PG, Crea F, Danchin N, Fox K, Maggioni AP, Manolis A, Marzilli M, Rosano GMC, Lopez-Sendon JL: Expert consensus document: a "diamond" approach to personalized treatment of angina. Nat Rev Cardiol 2018;15:120-132.

19 Heberden W: Some account of a disorder of the breast. Medical transitions. Royal College of Physiscians, 1772.

20 David AR, Kershaw A, Heagarty: Atherosclerosis and diet in ancient Egypt. Lancet 2010; 375;718-719.

21 Gelb BD: History of our understanding of the causes of congenital heart disease. Circ Cardiovasc Genet 2015;8:529-536.

22 Murrel W: Nitro-glycerine in angina pectoris. Lancet 1879;1:80-81.
3 Black JW, Duncan WA, Shanks RG: Comparison of some properties of pronethalol and propranolol. Br J Pharmacol Chemother 1965;25:577-591.

24 Fleckeinstain A: History of calcium antagonists. Circ Res 1983;52:469-125.

25 Maddox TM, Reid KJ, Spertus JA, et al: Angina at 1 year after myocardial infarction: prevalence and associated findings. Arch Intern Med 2008;168:1310-1316.

26 Hemingway H, Lanfenberg C, Damant J, Frost C, Pyörälä K, Barrett-Conor E: Prevalence of angina in women versus men: a systematic review and meta-analysis of international variations across 31 countries. Circulation 2008; 117:1526-1536.

27 Rossi R, Nuzzo A, Origliani G, Modena MG: Prognostic role of flow- mediated dilation and cardiac risk factors in post-menopausal women. J Am Coll Cardiol 2008;51:997-1002.

28 Wilson PW, D’Agostino RB, Sullivan L, Parise H, Kannel WB: Over-weight and obesity as determinants of cardiovascular risk: the Framingham experience. Arch Intern Med 2002;162:1867-1872.

29 Roger VL, Go AS, Lloyd-Jones DM, et al: Heart disease and stroke statistics - 2012 update: a report from the American Heart Association. Circulation 2012;125:e2-e220.

30 Feldman DN, Gade CL, Slotwiner AJ, et al: Comparison of outcomes of percutaneous coronary interventions in patients of three age groups $(<60,60$ to 80 , and $>80$ years) (from the New York State Angio-Plasty Registry). Am J Cardiol 2006;98:1334-1339.

31 National Institutes of Health, National Heart, Lung, and Blood Institute: Morbidity and Mortality: 2012 Chart Book on Cardiovascular, Lung, Blood Diseases. Bethesda, NIH/National Heart, Lung, and Blood Institute, 2012.

32 Mozaffarian D, Benjamin EJ, Go AS, Arnett DK: Heart disease and stroke statistics - 2015 update: a report from the American Heart Association. Circulation 2015;131:e29-e322.

33 National Institutes of Health, National Heart, Lung, and Blood Institute: Incidence and Prevalence: 2006 Chart Book on Cardiovascular and Lung Diseases. Bethesda, NIH/National Heart, Lung, and Blood Institute, 2006.

34 Rousan TA, Mathew ST, Thadani U: Drug therapy for stable angina pectoris. Drugs 2017;77:265-284.

-35 Pocock SJ, Henderson SA, Clayton T, Lyman $\mathrm{GH}$, Chamberlain DA: Quality of life after coronary angioplasty or continued medical treatment for angina: three-year follow-up in the RITE-2 trial: randomized intervention treatment of Angina. J Am Coll Cardiol 2000; 35:907-914.

36 Tendera M, Chassany O, Ferrari R, Ford I, Steg PG, Tardif JC, Fox K: Quality of life with ivabradine in patients with angina pectoris: the study assessing the morbidity-mortality benefits of the if inhibitor ivabradine in patients with coronary artery disease quality of life substudy. Circ Cardiovasc Qual Outcomes 2016;9:31-38.
37 Javitz HS, Ward MM, Watson JB, Jaana M: Cost of illness of chronic angina. Am J Manag Care 2004;10(11 suppl):S358-S369.

-38 Epstein SE, Cannon RO 3rd: Site of increased resistance to coronary flow in patients with angina pectoris and normal epicardial coronary arteries. J Am Coll Cardiol 1986;8:459461.

39 Ferrari R: Coronary artery disease in 2012: revising common beliefs in the management of stable CAD. Nat Rev Cardiol 2013;10:65-66.

40 Ferrari R, Nesta F, Boraso A: Increased heart rate is detrimental: the myocardial metabolic theory. Eur Heart J Suppl 1999;1(H):24-28.

41 Nayler WG, Ferrari R, Poole-Wilson PA, Yepez CE: A protective effect of a mild acidosis an hypoxic heart muscle. J Mol Cell Cardiol 1979;11:1053-1071.

42 Visioli O, Cucchini F, Bolognesi R, Raddino R, Di Lisa F, Ferrari R: Reproducibility of metabolic parameters during atrial pacing stress in cad patients. J Mol Cell Cardiol 1981;13:96.

43 Sylven C: Mechanism of pain in angina pectoris: a critical review of the adenosine hypothesis. Cardiovasc Drugs Ther 1993;7:745759.

44 Crea F, Gaspardone A: New look at an old symptom: angina pectoris circulation. Circulation 1997;96:3766-3773.

45 Braunwald E, Sobel B: Coronary blood flow and myocardial ischemia; in Braunwald $\mathrm{E}$ (ed): Heart Disease and Textbook of Cardiovascular Medicine. Philadelphia, WB Saunders, 1998, p 1191.

46 Ferrari R, Balla C, Malagù M, Guardigli G, Morciano G, Bertini M, Biscaglia S, Campo G: Reperfusion Damage - A Story of Success, Failure, and Hope. Circ J 2017;81:131-141.

47 Levine GN, Bates ER, Blankenship JC, et al: 2011 ACCF/AHA/SCAI guideline for percutaneous coronary intervention: a report of the American College of Cardiology Foundation/ American Heart Association Task Force on Practice Guidelines and the Society for Cardiovascular Angiography and Interventions. J Am Coll Cardiol 2011;58:e44-e122.

48 Marzilli M, Huqi A, Morrone D: Persistent angina: the Araba Phoenix of cardiology. Am J Cardiovasc Drugs 2010;10(suppl 1):27-32.

49 Milo M, Nerla R, Tarzia P, Infusino F, Battipaglia I, Sestito A, Lanza GA, Crea F: Coronary microvascular dysfunction after elective percutaneous coronary intervention: correlation with exercise stress test results. Int J Cardiol 2013;168:121-125.

50 Henderson RA, Pocock SJ, Clayton TC, et al: Seven-year outcome in the RITA-2 trial: coronary angioplasty versus medical therapy. J Am Coll Cardiol 2003;42:1161-1170.

51 Alderman EL, Kip KE, Whitlow PL, et al: Native coronary disease progression exceeds failed revascularization as cause of angina after five years in the Bypass Angioplasty Revascularization Investigation (BARI). J Am Coll Cardiol 2004;44:766-774. 
52 Boden WE, O’Rourke RA, Teo KK, Hartigan PM, Maron DJ, Kostuk WJ, Knudtson M, Dada M, Casperson P, Harris CL, Chaitman BR, Shaw L, Gosselin G, Nawaz S, Title LM, Gau G, Blaustein AS, Booth DC, Bates ER, Spertus JA, Berman DS, Mancini GB, Weintraub WS: Optimal medical therapy with or without PCI for stable coronary disease. N Engl J Med 2007;356:1503-1516.

53 McGill HC Jr, McMahan CA, Zieske AW, et al: Association of coronary heart disease risk factors with microscopic qualities of coronary atherosclerosis in youth. Circulation 2000; 102:374-379.

54 Nicoli G, Scalone G, Crea F: Acute myocardial infarction with no obstructive coronary atherosclerosis: mechanism and management. Eur Heart J 2015;36:475-481.

-55 Tonino PA, De Bruyne B, Pijls NH, et al: Fractional flow reserve versus angiography for guiding percutaneous coronary intervention. N Engl J Med 2009;360:213-224.

56 Maseri A: Coronary artery spasm and thrombosis: Cardiovascular Clinics 14 No. 1. J R Soc Med 1985;78:178.

-57 Vermeltfoort IAC, Raijmakers PGHM, Riphagen II, et al: Definitions and incidence of cardiac syndrome X: review and analysis of clinical data. Clin Res Cardiol 2010;99:475481.

58 Lanza GA, Crea F: Primary coronary microvascular dysfunction: clinical presentation pathophysiology and management. Circulation 2010;121:2317-2325.

\$59 Marinescu MA, Löffler AI, Ouellette M, Smith L, Kramer CM, Bourque JM: Coronary microvascular dysfunction, microvascular angina, and treatment strategies. JACC Cardiovasc Imaging 2015;8:210-220.

-60 Sedlak T, Izadnegahdar M, Humphries KH, Bairey Merz CN: Sex-specific factors in microvascular angina. Can J Cardiol 2014;30: 747-755.

61 Paul TK, Sivanesan K, Schulman-Marcus J: Sex differences in nonobstructive coronary artery disease: recent insights and substantial knowledge gaps. Trends Cardiovasc Med 2017;27:173-179.

- 62 Jespersen L, Hvelplund A, Abildstrom SZ, Pedersen F, Galatius S, Madsen JK, Jorgensen E, Kelbaek H, Prescott E: Stable angina pectoris with no obstructive coronary artery disease is associated with increased risks of major adverse cardiovascular events. Eur Heart J 2012; 33:734-744.

-63 Tschope C, Van LS: New insights in (inter) cellular mechanisms by heart failure with preserved ejection fraction. Curr Heart Fail Rep 2014;11:436-444.

-64 Crea F, Bairey Merz CN, Beltrame JF, Kaski JC, Ogawa H, Ong P, Sechtem U, Shimokawa H, Camici PG; Coronary Vasomotion Disorders International Study Group (COVADIS): The parallel tales of microvascular angina and heart failure with preserved ejection fraction: a paradigm shift. Eur Heart J 2017;38:473477.
65 Paulus WJ, Tschope C: A novel paradigm for heart failure with preserved ejection fraction: comorbidities drive myocardial dysfunction and remodeling through coronary microvascular endothelial inflammation. J Am Coll Cardiol 2013;62:263-271.

66 Mohammed SF, Hussain S, Mirzoyev SA, Edwards WD, Maleszewski JJ, Redfield MM: Coronary microvascular rarefaction and myocardial fibrosis in heart failure with preserved ejection fraction. Circulation 2015; 131:550-559.

67 Pries AR, Reglin B: Coronary microcirculatory pathophysiology: can we afford it to remain a black box? Eur Heart J 2017;38:478-488.

68 Johnston N, Schenck-Gustafsson K, Lagerqvist B: Are we using cardiovascular medications and coronary angiography appropriately in men and women with chest pain? Eur Heart J 2011;32:1331-1336.

69 Guarini G, Huqi A, Morrone D, Capozza P, Todiere G, Marzilli M: Pharmacological approaches to coronary microvascular dysfunction. Pharmacol Ther 2014;144:283-302.

70 Crea F, Camici PG, Bairey Merz CN: Coronary microvascular dysfunction: an update. Eur Heart J 2014;35:1101-1111.

71 Pries AR, Badimon L, Bugiardini R, Camici PG, Dorobantu M, Duncker DJ, Escaned J, Koller A, Piek JJ, de Wit C: Coronary vascular regulation, remodelling, and collateralization: mechanisms and clinical implications on behalf of the working group on coronary pathophysiology and microcirculation. Eur Heart J 2015;36:3134-3146.

72 Heusch G, Baumgart D, Camici P, Chilian W, Gregorini L, Hess O, Indolfi C, Rimoldi O: Alpha-adrenergic coronary vasoconstriction and myocardial ischemia in humans. Circulation 2000;101:689-694.

73 Egashira K, Inou T, Hirooka Y, Yamada A, Urabe Y, Takeshita A: Evidence of impaired endothelium-dependent coronary vasodilatation in patients with angina pectoris and normal coronary angiograms. N Engl J Med 1993;328:1659-1664.

74 Camici PG, d'Amati G, Rimoldi O: Coronary microvascular dysfunction: mechanisms and functional assessment. Nat Rev Cardiol 2015; 12:48-62.

75 Duncker DJ, Bache RJ: Regulation of coronary blood flow during exercise. Physiol Rev 2008;88:1009-1086.

-76 Suzuki H, Takeyama Y, Koba S, Suwa Y, Katagiri T: Small vessel pathology and coronary hemodynamics in patients with microvascular angina. Int J Cardiol 1994;43:139-150.

77 Reglin B, Pries AR: Metabolic control of microvascular networks: oxygen sensing and beyond. J Vasc Res 2014;51:376-392.

78 Porro B, Eligini S, Veglia F, Lualdi A, Squellerio I, Fiorelli S, Giovannardi M, Chiorino E, Dalla CA, Crisci M, Werba JP, Tremoli E, Cavalca V: Nitric oxide synthetic pathway in patients with microvascular angina and its relations with oxidative stress. Oxid Med Cell Longev 2014;2014:726539.
79 Borer JS, Swedberg K, Komajda M, Ford I, Tavazzi L, Böhm M, Depre C, Wu Y, Maya J, Dominjon F: Efficacy profile of ivabradine in patients with heart failure plus angina pectoris. Cardiology 2016;136:138-144.

80 Opie LH, Sonnenblick EH, Frishman W, Thadani U: Beta Blockers: Drugs for the Heart. Philadelphia, WB Saunders, 1995, pp 1-27.

81 Husted SE, Ohman EM: Pharmacological and emerging therapies in the treatment of chronic angina. Lancet 2015;386:691-701.

82 Amosova E, Andrejev E, Zaderey I, Rudenko U, Ceconi C, Ferrari R: Efficacy of ivabradine in combination with beta-blocker versus uptitration of beta-blocker in patients with stable angina. Cardiovasc Drugs Ther 2011; 2015;25:531-537.

83 DiFrancesco D, Camm JA: Heart rate lowering by specific and selective I(f) current inhibition with ivabradine: a new therapeutic perspective in cardiovascular disease. Drugs 2004;64:1757-1765.

84 Borer JS, Heuzey JY: Characterization of the heart rate-lowering action of ivabradine, a selective I(f) current inhibitor. Am J Ther 2008; 15:461-473.

85 Tagliamonte E, Cirillo T, Rigo F, et al: Ivabradine and bisoprolol on Doppler-derived coronary flow velocity reserve in patients with stable coronary artery disease: beyond the heart rate. Adv Ther 2015;32:757-767.

86 Gloekler S, Traupe T, Stoller M, et al: The effect of heart rate reduction by ivabradine on collateral function in patients with chronic stable coronary artery disease. Heart 2014; 100:160-166

87 Jedlickova L, Merkovska L, Jackova L, et al: Effect of ivabradine on endothelial function in patients with stable angina pectoris: assessment with the Endo-PAT 2000 device. Adv Ther 2015;32:962-970.

-88 Tardif JC, Ponikowski P, Kahan T; ASSOCIATE Study Investigators: Efficacy of the If current inhibitor ivabradine in patients with chronic stable angina receiving beta-blocker therapy: a 4-month, randomized, placebocontrolled trial. Eur Heart J 2009;30:540-548.

89 Fox K, Ford I, Steg PG, Tendera M, Ferrari R; BEAUTIFUL Investigators: Ivabradine for patients with stable coronary artery disease and left-ventricular systolic dysfunction (BEAUTIFUL): a randomised, double-blind, placebo-controlled trial. Lancet 2008;372: 807-816.

90 Fox K, Ford I, Steg PG, Tendera M, Robertson $\mathrm{M}$, Ferrari R; BEAUTIFUL investigators: Relationship between ivabradine treatment and cardiovascular outcomes in patients with stable coronary artery disease and left ventricular systolic dysfunction with limiting angina: a subgroup analysis of the randomized, controlled BEAUTIFUL trial. Eur Heart J 2009; 30:2337-2345.

91 Fox K, Ford I, Steg PG, Tardif JC, Tendera M, Ferrari R: Ivabradine in stable coronary artery disease without clinical heart failure. $\mathrm{N}$ Engl J Med 2014;371:1091-1099. 
-92 Tardif JC, Ponikowski P, Kahan T, et al: Effect of verapamil on mortality and major events after acute myocardial infarction (the Danish Verapamil Infarction Trial II - DAVIT II). Am J Cardiol 1990;66:779-785.

93 Frishman WH, Sica DA: Calcium channel blockers; in Frishman WH, Sonnenblick EH, Sica DA (eds): Cardiovascular Pharmacotherapeutics. New York, McGraw-Hill, 2003.

94 Bangalore S, Makani H, Radford M, Thakur K, Toklu B, Katz SD, et al: Clinical outcomes with beta-blockers for myocardial infarction: a meta-analysis of randomized trials. Am J Med 2014;127:939-953.

-95 Antman E, Muller J, Goldberg S, MacAlpin R, Rubenfire M, Tabatznik B, et al: Nifedipine therapy for coronary-artery spasm: experience in 127 patients. N Engl J Med 1980;302 1269-1273.

-96 Poole-Wilson PA, Lubsen J, Kirwan BA, van Dalen FJ, et al: Effect of long-acting nifedipine on mortality and cardiovascular morbidity in patients with stable angina requiring treatment (ACTION trial): randomised controlled trial. Lancet 2004;364:849-857.

-97 Johnston N, Schenck-Gustafsson K, Lagerqvist B: Are we using cardiovascular medications and coronary angiography appropriately in men and women with chest pain? Eur Heart J 2011;32:1331-1336.

-98 Chrysant SG, Glasser SP, Bittar N, Shahidi FE, Danisa K, Ibrahim R, et al: Efficacy and safety of extended-release isosorbide mononitrate for stable effort angina pectoris. Am J Cardiol 1993;72:1249-1256.

99 O’Rourke ST: Nitro vasodilators: pharmacology and use in the treatment of myocardial ischemia. Am J Pharm Educ 2002;66:177180.
100 Munzel T, Daiber A, Gori T: Nitrate therapy: new aspects concerning molecular action and tolerance. Circulation 2011;123:21322144.

101 Suryapranata H, Serruys PW, De Feyter PJ, Verdouw PD, Hugenholtz PG: Coronary vasodilatory action after a single dose of nicorandil. Am J Cardiol 1988;61:292-297.

102 Camm AJ, Maltz MB: A controlled singledose study of the efficacy, dose response and duration of action of nicorandil in angina pectoris. Am J Cardiol 1989;63:61J-65J.

103 The IONA Study Group: Effect of nicorandil on coronary events in patients with stable angina: the Impact of Nicorandil in Angina (IONA) randomised trial. Lancet 2002;359: 1269-1275.

104 Kantor PF, Lucien A, Kozak R, Lopaschuk GD: The antianginal drug trimetazidine shifts cardiac energy metabolism from fatty acid oxidation to glucose oxidation by inhibiting mitochondrial long-chain 3-ketoacyl coenzyme A thiolase. Circ Res 2000;86:580588.

105 Fragasso G, Perseghin G, De CF, et al: Effects of metabolic modulation by trimetazidine on left ventricular function and phosphocreatine/adenosine triphosphate ratio in patients with heart failure. Eur Heart J 2006;27: 942-948.

106 Peng S, et al: The efficacy of trimetazidine on stable angina pectoris: a meta-analysis of randomized clinical trials. Int J Cardiol 2014;177:780-785.

107 Ciapponi A, Pizarro R, Harrison J: Trimetazidine for stable angina. Cochrane Database Syst Rev 2017;20:CD003614.

108 Kim JS, Kim CH, Chun KJ, et al: Effects of trimetazidine in patients with acute myocardial infarction: data from the Korean Acute Myocardial Infarction Registry. Clin Res Cardiol 2013;102:915-922.
09 Marazzi G, Wajngarten M, Vitale C, et al: Effect of free fatty acid inhibition on silent and symptomatic myocardial ischemia in diabetic patients with coronary artery disease. Int J Cardiol 2007;120:79-84.

110 Gao D, Ning N, Niu X, Hao G, Meng Z: Trimetazidine: a meta-analysis of randomised controlled trials in heart failure. Heart 2011;97:278-286.

111 Rayner E, Hartley, Sedlak T: Ranolazine: a contemporary review. J Am Heart Assoc 2016;5:e003196.

112 Weisz G, Farzaneh-Far R, Ben-Yehuda O, Debruyne B, Montalescot G, Lerman A, et al: Use of ranolazine in patients with incomplete revascularization after percutaneous coronary intervention: design and rationale of the Ranolazine for Incomplete Vessel Revascularization Post-Percutaneous Coronary Intervention (RIVER-PCI) trial. Am Heart J 2013;166:953-959.e3.

113 Morrow DA, Scirica BM, Karwatowska-Prokopczuk E, Murphy SA, Budaj A, Varshavsky S, Wolff AA, Skene A, McCabe $\mathrm{CH}$ Braunwald E; MERLIN-TIMI 36 Trial Investigators: Effects of ranolazine on recurrent cardiovascular events in patients with non-ST-elevation acute coronary syndromes: the MERLIN-TIMI 36 randomized trial. JAMA 2007;297:1775-1783.

114 Bairey Merz CN, Handberg EM, Shufelt CL, Mehta PK, Minissian MB, Wei J, et al: A randomized, placebo-controlled trial of late $\mathrm{Na}$ current inhibition (ranolazine) in coronary microvascular dysfunction (CMD): impact on angina and myocardial perfusion reserve. Eur Heart J 2016;37:1504-1513. 